\title{
Comparison of the median effective concentration (EC50) and effect of sevoflurane with or without remifentanil in cesarean section with supreme laryngeal mask under narcotrend monitoring: a randomized trial
}

\author{
Jian-Feng Lian", Yi-Bin Xu", Bin-Yao Zheng, Long-Yuan Shen, Dao-Yong Liao, Chang Zheng, \\ Cai-Ling Lin, Ci-Bin Huang, Qi-Chen Luo, Guo-Qing Guo, Xiong-Da Lin, Jian-Wen Wu, Quan-Sheng Xiao \\ Department of Anesthesiology, Quanzhou Women's and Children's Hospital, Quanzhou, China \\ Contributions: (I) Conception and design: JF Lian, YB Xu, JW Wu, QS Xiao; (II) Administrative support: JW Wu; (III) Provision of study materials \\ or patients: BY Zheng, QC Luo, GQ Guo, XD Lin; (IV) Collection and assembly of data: BY Zheng, LY Shen, DY Liao, C Zheng; (V) Data analysis \\ and interpretation: CL Lin, CB Huang; (VI) Manuscript writing: All authors; (VII) Final approval of manuscript: All authors. \\ \#These authors contributed equally to this work. \\ Correspondence to: Dr. Jian-Wen Wu; Dr. Quan-Sheng Xiao. Department of Anesthesiology, Quanzhou Women's and Children's Hospital, 700 Feng \\ Ze Road, Quanzhou 362000, China. Email: 20514957@qq.com; xiaoquansheng58_qz@163.com.
}

Background: Remifentanil combined with sevoflurane is a standard protocol for obstetric general
anesthesia (GA).
Methods: In this study, we performed a randomized clinical trial to evaluate whether remifentanil has an
effect on the median effective concentration (EC50) of sevoflurane and compare anesthetic outcomes of
them in cesarean section with Supreme ${ }^{\mathrm{TM}}$ laryngeal mask airway (SLMA) under narcotrend monitoring.
Ninety parturients with singleton births undergoing elective cesarean delivery (CD) with initial inhaled
1.0 minimum alveolar concentration (MAC) sevoflurane for anesthesia maintenance were assigned to three
groups randomly and evenly: Group A (0.05 $\mu \mathrm{gg}^{-1} \cdot \mathrm{min}^{-1}$ remifentanil combined with sevoflurane), Group
B (0.1 $\mu \mathrm{g} \cdot \mathrm{kg}^{-1} \cdot \mathrm{min}^{-1}$ remifentanil combined with $\mathrm{sevoflurane}$ ), and Group C (normal saline combined with $_{\text {sevoflurane). Narcotrend was used to monitor the depth of anesthesia during the operation, with the level }}$ of anesthesia depth controlled within the D-E stage. The EC50 of sevoflurane was determined by Dixon's
sequential method. The Narcotrend index, amount of bleeding, neonatal Apgar score, and corresponding
treatment measures in the three groups were recorded.

Results: The results showed that the estimated EC50 of sevoflurane for obstetric GA was 0.80 MAC (95\% CI: 0.63-0.95 MAC) in group A, 0.82 MAC (95\% CI: 0.63-0.96 MAC) in group B, and 0.80 MAC (95\%

CI: 0.63-0.95 MAC) in group C. There was no statistically significant difference in the estimated EC50 of sevoflurane, time to wakefulness, Apgar score, amount of intraoperative bleeding, and postoperative bleeding within 24 hours between the three groups (all $\mathrm{P}>0.05$ ).

Conclusions: The addition of remifentanil at $0.05-0.1 \mu \mathrm{g} \cdot \mathrm{kg}^{-1} \cdot \mathrm{min}^{-1}$ did not change the EC50 of sevoflurane and anesthetic quality. The concentration of inhaled anesthetics can be minimized with Narcotrend monitoring.

Trial Registration: Chinese Clinical Trial Registry ChiCTR2000034512. Keywords: Sevoflurane; remifentanil; cesarean section; median effective concentration; minimum alveolar
concentration (MAC)

Submitted Aug 31, 2021. Accepted for publication Nov 17, 2021.

doi: 10.21037/apm-21-2664

View this article at: https://dx.doi.org/10.21037/apm-21-2664 


\section{Introduction}

Although cesarean delivery (CD) has shown a decline in recent decades $(1,2)$, the rate of $C D$ remains high worldwide (3): $32.2 \%$ in United States in 2014 (4), $34.9 \%$ in China in 2014 (5), highly $56 \%$ in Brazil in 2015 (6). Compared with neuraxial anesthesia (NA), general anesthesia (GA) is not the first choice for most CDs with disadvantage of higher risks for anesthesiarelated complications, surgical site infection, venous thromboembolic events, and postoperative pain (7-9), but it is still used in the condition of patients preference (10), emergency $\mathrm{CD}$ or patients contraindications to NA, such as severe placental abruption, ruptured uterus, or severe hemorrhage $(7,8)$. The estimated current GA rate for $\mathrm{CD}$ is $5.5 \%(11,12)$. Whereas, newly developed drugs, instruments, and monitors have brought dramatic improvements to the overall safety of GA (13).

The newly Supreme laryngeal mask airway (SLMA) is more easily and safer than endotracheal intubation (ETT) in aspect of intubation operation (14), by means of a doublelumen system that could separate the respiratory and alimentary tracts to attenuate and prevent gastric fluid at the hypopharynx from entering the airway $(15,16)$. Previous studies have shown that the SLMA first attempt insertion success rate under GA in urgent or elective CD (17-19) was greater than $98 \%$ with only rare airway complications, such as regurgitation or aspiration. Furthermore, SLMA reduces ventilation time and hemodynamic changes compared with ETT (19). Considering those advantages, SLMA for GA in $\mathrm{CD}$ is routinely practiced in our anesthesia department and was also used in this study.

Pharmacological options, dosage and regime of anesthetic agents for $\mathrm{CD}$ have been the focus of many studies because of the concern that its safety and effectiveness play an essential role in maternal and fetal outcomes (20-23). Sevoflurane and remifentanil are the most widely used anesthetic agents. Both are characterized by rapid onset and offset $(24,25)$. On one hand, sevoflurane is generally used as a sedative for intravenous-induced anesthesia or maintenance anesthesia. Remifentanil is a useful adjunct for improving maternal hemodynamic stability during GA for CD. A single bolus of $1 \mu \mathrm{g} / \mathrm{kg}$ remifentanil effectively attenuated hemodynamic changes after induction and tracheal intubation (20). A latest research has compared the effect of remifentanil used different doses (low-dose: $<1 \mathrm{mcg} / \mathrm{kg}$; high-dose: $\geq 1 \mathrm{mcg} / \mathrm{kg}$ ) on haemodynamic instability in parturient women with hypertensive disorders of pregnancy. The results have showed that high dose of remifentanil was significantly more effective than low dose of remifentanil in controlling systolic arterial pressure (23). However, high dose of remifentanil may result in delayed respiratory depression in newborns (20). Pournajafian et al. found that an infusion rate of $0.05 \mu \mathrm{g} / \mathrm{kg} / \mathrm{min}$ remifentanil may effectively attenuate the pressor response to tracheal intubation in severely preeclamptic patients (26). On the other hand, remifentanil is commonly used as an analgesic for inhaled maintenance anesthesia. In terms of intraoperative awareness, an endtidal sevoflurane concentration of $1.2-1.5 \%$ should be administered as assessed by the bispectral index to ensure adequate depth of anesthesia in CD (27-29). Nevertheless, volatile anesthetics have a dose-dependent tocolytic effect (30). In a previous study, sevoflurane depressed isolated pregnant human myometrium contractility at concentrations of 0.5 (1.0\% vol), 1.0, and 1.5 MAC in vitro (31). Therefore, cautious dosing of remifentanil and sevoflurane must be considered to reduce the amount of sevoflurane and yet still maintain a desirable anesthetic effect.

Previous studies have demonstrated that dexmedetomidine reduces sevoflurane EC50 (32). For example, Savla et al. found that intranasal dexmedetomidine premedications significantly reduce the sevoflurane EC50 for LMA insertion in children by $21 \%$ (32). Similarly, in spontaneous breathing morbidly obese patients, intravenous dexmedetomidine can reduce sevoflurane EC50 for successful supraglottic airway device insertion by about $40 \%$ (33). A recent study concluded that the clinical efficacy of sevoflurane combined with remifentanil anesthesia is better than that of propofol combined with remifentanil, and it can effectively reduce the stress of pregnant women with pregnancy-induced hypertension treated with cesarean section (34). The use of remifentanil in combination with sevoflurane in obstetric general anesthesia is a standard regimen, but little knowledge is available regarding the interaction between sevoflurane and remifentanil.

The Narcotrend index correlates well with the depth of anesthesia of inhaled anesthetics, and the depth of anesthesia is dependent on the drug dose (35). With the advantage of our extensive experience with SLMA in our department and Narcotrend monitoring, we have designed this randomized, double-blind, controlled trial to assess the median effective concentration (EC50) of remifentanil with or without sevoflurane in $\mathrm{CD}$. We also aimed to explore the interaction between sevoflurane and remifentanil. We present the following article in accordance with the CONSORT reporting checklist (available at https://dx.doi. 
org/10.21037/apm-21-2664).

\section{Methods}

\section{Patients and study design}

We designed the study as prospective, randomized, controlled, and three blind. Random numbers between 1-90 were generated by Excel (Microsoft 2013) and were sequentially sealed in an envelope, which were blind for subjects, implementers (designated nurses), and anesthesiologists. Before the operation, designated nurses gave each subject a sealed envelope with a random number in it. Anesthesiologists performs three-arm parallel grouped anesthesia according to a previously designed distribution plan: group A [1-30], group B [31-60], group C [61-90], with the $1: 1: 1$ allocation ratio. This study has been approved by the Ethics Committee of Quanzhou Women's and Children's Hospital (No. 2020-1). All procedures performed in this study involving human participants were in accordance with the Declaration of Helsinki (as revised in 2013). Parturients with singleton and full-term pregnancies undergoing elective CD were recruited from the Obstetrics Department of the Quanzhou Women's and Children's Hospital in China from June 2019 to May 2020. Ninety parturients aged $\geq 18$ years, who had an American Society of Anesthesiologists (ASA) I-II physical status, were at full term, and who gave informed consent to participate were included in the study. The exclusion criteria were as follows: (I) patients known to have language disorders, psychological disorders, or cognitive dysfunction; (II) patients suffering from heart, lung, liver, kidney or other organ diseases, hemorrhagic diseases, neuromuscular diseases, gastroesophageal reflux disease, or other systemic diseases (selfreported); (III) patients with a body mass index (BMI) $\geq 35 \mathrm{~kg} / \mathrm{m}^{2}$ or a potentially difficult airway (modified Mallampati grade 4, upper respiratory tract, or neck pathology); (IV) patients known to have an intrauterine restriction or fetal damage; (V) patients with alcohol or any substance addictions; (VI) pregnancy complicated with myasthenia gravis, bronchial asthma, diabetes, hypertension, or hypotension; and (VII) patients allergic to any of the local or general anesthetic agents used in the study. Patients included in the study were randomly divided into three groups, with 30 patients in each group: Group A $\left(0.05 \mu \mathrm{g} \cdot \mathrm{kg}^{-1} \cdot \mathrm{min}^{-1}\right.$ remifentanil combined with sevoflurane), Group B $\left(0.1 \mu \mathrm{g} \cdot \mathrm{kg}^{-1} \cdot \mathrm{min}^{-1}\right.$ remifentanil combined with sevoflurane), and Group C (normal saline combined with sevoflurane).

\section{Anestbetic management}

All parturients were strictly fasted for 6-8 h and were forbidden to drink for $2 \mathrm{~h}$ before surgery. From the time of arrival at the operating room to the end of the procedure, all patients lay on their left side at $30^{\circ}$ to reduce the compression of the inferior vena cava and the abdominal aorta by the uterus and prevent the occurrence of supine hypotension syndrome. Firstly, a peripheral venous route in the forearm was established and lactated Ringer's (LR) solution was continuously infused to keep the vein open. Meanwhile, patients were administered oxygen via a face mask and received continuous monitoring of anesthesia depth with the use of electrocardiogram (ECG), noninvasive arterial pressure (NIBP), heart rate (HR), and peripheric oxygen saturation $\left(\mathrm{SpO}_{2}\right)$ measures, as well as an end-tidal gas analyzer. After pre-oxygenation, anesthesia was induced intravenously with propofol $(2 \mathrm{mg} / \mathrm{kg})$ and rocuronium $(0.5 \mathrm{mg} / \mathrm{kg})$, followed by a graded dose of remifentanil. Patients in groups $\mathrm{A}$ and $\mathrm{B}$ received a steady dose of 0.05 and $0.1 \mu \mathrm{g} \cdot \mathrm{kg}^{-1} \cdot \mathrm{min}^{-1}$ intravenous remifentanil, respectively, and those in group $\mathrm{C}$ received intravenous normal saline instead of remifentanil. One min after completing the anesthesia induction, the SLMA was inserted and connected with an anesthesia machine for mechanical ventilation. Anesthesia was maintained with sevoflurane, in combination with $50 \% \mathrm{~N} 2 \mathrm{O}$ in oxygen, using a circuit with a fresh gas flow of 8 liters. $\mathrm{min}^{-1}$ until the time of delivery. After connection of the circuit to the tracheal tube, sevoflurane was administered, followed by adjustment to maintain the target anesthesia depth (Narcotrend stage D-E). The $\mathrm{EC}_{50}$ was calculated using the series of up-and-down sequentially allocated doses (known as the Dixon up-and-down sequential allocation method). The initial concentration of sevoflurane inhaled in each group was 1.0 MAC that was automatically converted by the Drager anesthesia machine based on age. If the Narcotrend stage was less than level $\mathrm{D}_{0}$ (regarded as "negative"), the subsequent concentration was reduced by $0.1 \mathrm{MAC}$. If the Narcotrend stage was greater than level $\mathrm{D}_{0}$ (regarded as "positive"), the subsequent concentration was increased by $0.1 \mathrm{MAC}$. After reaching the target Narcotrend stage for $1 \mathrm{~min}$, the operation began. After delivery, the patient was given fentanyl $(50 \mu \mathrm{g} /$ time $)$ according to the changes of blood pressure and heart rate to deepen anesthesia or hydroxyethyl starch to expand capacity, 


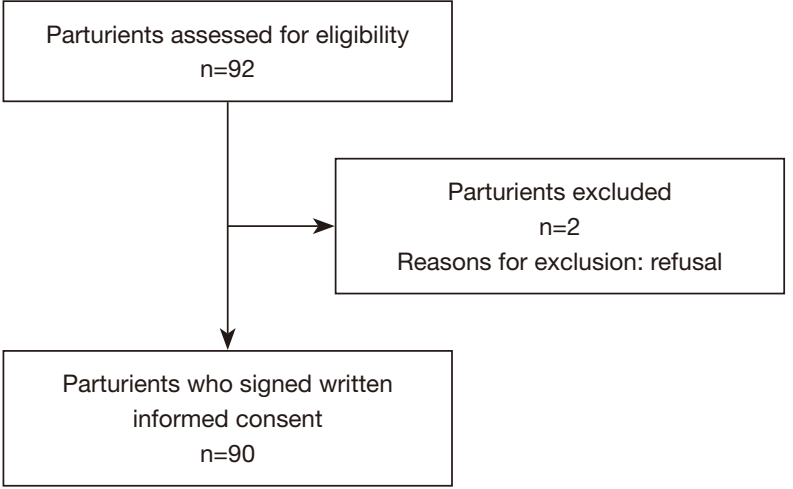

Figure 1 Flow diagram of participant enrollment.

and deoxyepinephrine (50 $\mu \mathrm{g} /$ time) to increase blood pressure so as to maintain stable hemodynamics during the operation. After removal of the placenta, a myometrium injection of oxytocin was performed routinely to promote uterine contractions. When the skin suturing was finished, volatile anesthetics were discontinued, and neuromuscular blockade antagonized with neostigmine and extubation were performed when the patient was fully awake and had returned to the ward.

\section{Data collection}

The data recorded for inclusion in the statistical comparisons included the Narcotrend index, the amount of intravenous and inhaled anesthetics used, the amount of intraoperative and postoperative bleeding, the time from skin incision to delivery (C-D time), the time from induction to delivery (I-D time), the time from withdrawal of anesthetics to patient wakefulness, and the Apgar score at 1,5 , and $10 \mathrm{~min}$ after delivery. Our primary outcome was EC50 of sevoflurane. Secondary anesthetic outcomes included: newborn Apgar scores at both 1 and $5 \mathrm{~min}$, maternal time to wakefulness, intraoperative bleeding, and postoperative bleeding within $24 \mathrm{~h}$ of delivery.

\section{Statistical analysis}

Continuous variables with a normal distribution are presented as the mean and standard deviation (SD) and were analyzed using a one-way analysis of variance (ANOVA). Continuous variables not normally distributed are presented as the median $(\mathrm{M})$ and were analyzed using the nonparametric Kruskal-Wallis test. Categorical variables are presented as count and proportion and were analyzed using the Chi-square or Fisher's exact test. All data were analyzed using IBM SPSS 20.0 software (Chicago, IL, USA). All statistical tests were performed as two-sided tests, where a $\mathrm{P}$ value $<0.05$ was considered statistically significant. The EC50 was calculated using a Probit regression. The Pearson goodness-of-fit test showed that the established probit model was a good fit $(\mathrm{P}>0.05)$. Parallel tests showed that each group had the same slope $(\mathrm{P}>0.05)$, so the probit model was established and estimated using the same slope model.

The model is described as follows:

$$
\begin{aligned}
\operatorname{PROBIT}(\mathrm{p})= & -2.894(\mathrm{~A})-2.971(\mathrm{~B}) \\
& -2.917(\mathrm{C})+3.627 * \mathrm{MAC}
\end{aligned}
$$

\section{Results}

\section{Characteristics of included participants}

Ninety of initial 92 enrolled parturients completed the study, and 2 parturients were lost to because of refusal (Figure 1). The participants' demographic and clinical characteristics are shown in Table 1. There was no significant difference in age, gestational week, BMI, number of previous cesarean sections, I-D time, or C-D time between the three groups $(\mathrm{P}<0.05)$.

\section{EC50 of sevoflurane}

When the Narcotrend stage was below the D range during the cesarean operation under GA, the EC50 of sevoflurane among Groups A, B, and C was 0.80 MAC (95\% CI: $0.63-$ $0.95 \mathrm{MAC}$ ), 0.82 MAC (95\% CI: 0.63-0.96 MAC), and 0.80 MAC (95\% CI: 0.63-0.95 MAC), respectively, and showed no significant between-group difference (as shown in Table 2 and Figure 2).

\section{The effect of a graded dose of remifentanil combined with sevoflurane on the maternal and newborn status}

The newborn Apgar scores at both 1 and 5 min among the three groups did not differ significantly (Table 3, both $\mathrm{P}>0.05)$. Maternal time to wakefulness, intraoperative bleeding, and postoperative bleeding within $24 \mathrm{~h}$ of delivery among the three groups did not differ significantly (Table 3, all $\mathrm{P}>0.05)$.

\section{Discussion}

The choice of anesthesia for cesarean section plays a 
Table 1 The demographic and clinical characteristics of patients

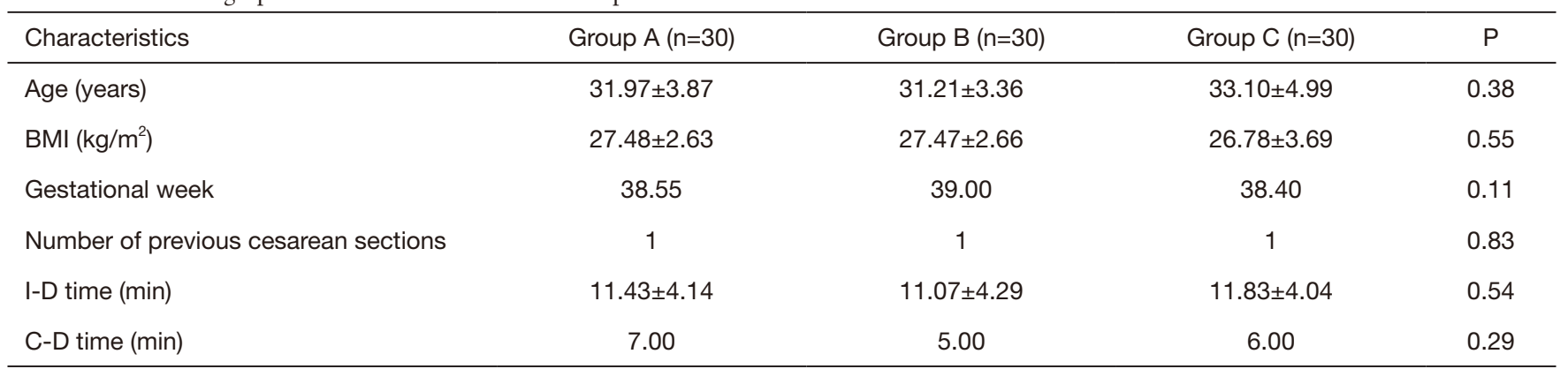

Data are mean \pm SD. BMI, body mass index.

Table 2 Comparisons of EC50 and the $95 \%$ CI of sevoflurane among the three groups

\begin{tabular}{lccc}
\hline Group & EC50 (MAC) & $95 \%$ Cl (MAC) & P value of Kolmogorov-Smirnov test (two-side) \\
\hline A & 0.80 & $0.63-0.95$ & 0.22 \\
B & 0.82 & $0.63-0.96$ & 0.24 \\
C & 0.80 & $0.63-0.95$ & 0.36 \\
\hline
\end{tabular}

EC50, the median effective concentration; MAC, minimum alveolar concentration.

significant role in maternal and fetal outcomes (11). The high global rate of CD (3-6) requires ongoing efforts to improve the quality and safety of GA for all pregnant women undergoing planned or unplanned CD. In this study, we sought to define the optimum compatibility concentration of sevoflurane and remifentanil.

Historically, the depth of anesthesia of patients has been judged by HR, blood pressure (BP), and limb movements, but these clinical signs are unreliable. In addition, monitoring of brain activity has also been lacking. The introduction of Narcotrend monitoring has solved this problem as it is a sensitive and specific monitor that accurately reflects the depth of inhaled anesthetic utilizing the dose-response relationship (36). Thus, Narcotrend electroencephalogram monitoring is an important method to guide the amount of inhaled anesthetic to avoid intraoperative awareness. This study demonstrated that, as measured by the bispectral index in CD, the EC50 of sevoflurane required to maintain the index at or below grade $\mathrm{D}$ is approximately 0.80 MAC (95\% CI: 0.63-0.95 MAC), and the EC95 of sevoflurane at the same depth is 0.95 MAC. The concentration is far lower than the 1.3 MAC used for general surgery (37), suggesting that the sensitivity of sevoflurane in pregnant women differs from that in nonpregnant women as measured by electroencephalogram monitoring. This may be due to the decreased sensitivity to pain in full-term pregnancy and the resulting reduced demand for anesthesia and analgesia compared with nonpregnant women (38). However, this theory conflicts with the findings of a previous electroencephalographic study showing that pregnancy does not enhance volatile anesthetic sensitivity on the brain, and hence does not enhance the hypnotic effect of sevoflurane (39).

Sevoflurane $1.5 \%$ is more often administered with other agents, such as opioids, rather than as a single dose at high concentration. But with Narcotrend monitoring, it is unclear whether remifentanil influences the EC50 of sevoflurane. Our study showed that neither $0.05 \mu \mathrm{g} \cdot \mathrm{kg}^{-1} \cdot \mathrm{min}^{-1}$ nor $0.1 \mu \mathrm{g} \cdot \mathrm{kg}^{-1} \cdot \mathrm{min}^{-1}$ remifentanil changed the EC50 of sevoflurane at the same Narcotrend index. This seems to differ from other studies that indirectly measured the depth of anesthesia by monitoring involuntary limb activity, HR, or BP. The mechanisms of Narcotrend monitoring and remifentanil may have contributed to the disparity. Narcotrend works by monitoring the potential activity of the cerebral cortex (mainly the frontal lobe), not the thalamus and spinal cord, whereas remifentanil acts on opioid receptors that are mainly distributed in the subcortex and spinal cord (40). Therefore, the pharmacological effects of remifentanil may not be reflected by Narcotrend monitoring.

Effective GA requires a good combination of sedation, 

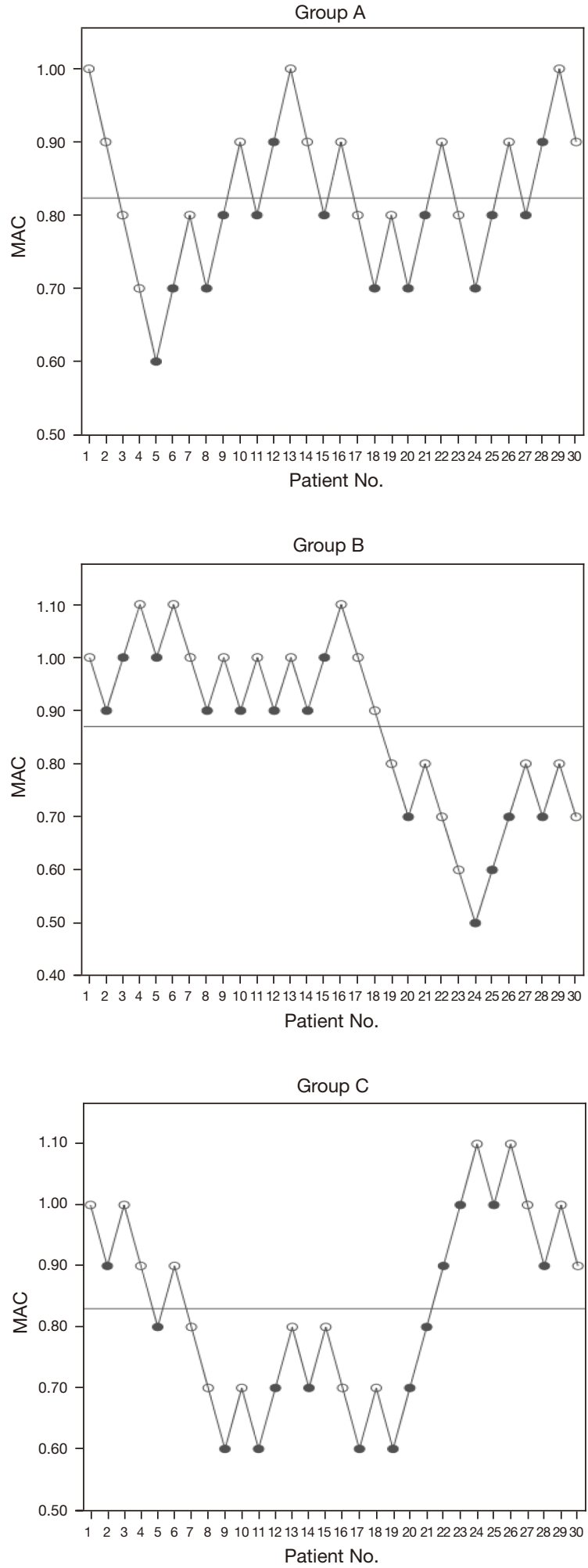

Figure 2 Scatter plot demonstrating dosages reported as effective (solid) and ineffective (hollow) for all 90 participants. The horizontal line represents the ED50. analgesia, and muscular flaccidity. Sevoflurane, a sedative drug, has a blood/gas distribution coefficient of 0.63-0.69, which can be induced by anesthesia and removed quickly, with little influence on respiration and hemodynamics. Besides having a strong sedative effect, sevoflurane also has particular analgesic and muscle relaxant properties, ensuring a better safety profile. Pre-exposure to low concentrations of sevoflurane may reduce the risk of maternal intraoperative awareness in the interval before delivery (41). Volatile anesthetics have dose-dependent effects on uterine relaxation, and high concentrations of volatile anesthetics may increase unnecessary obstetric bleeding (13). As a short-acting opioid agonist, remifentanil is recommended as an analgesic for GA during cesarean sections $(42,43)$. It can cross the placenta rapidly, and at the same time it can be rapidly eliminated from the neonatal circulation by plasma non-specific esterase degradation and/or redistribution (44). Studies of obstetric and non-obstetric surgeries have provided clear evidence that the use of remifentanil can maintain hemodynamic stability and avoid hypertension and tachycardia (24). A single bolus of $1 \mu \mathrm{g} / \mathrm{kg}$ remifentanil was found to effectively attenuate hemodynamic changes after induction and tracheal intubation (20). Continuous pumping of remifentanil may have adverse effects on mothers and newborns. This study demonstrated that different doses of remifentanil in combination with sevoflurane did not negatively affect the Apgar score or maternal blood loss. Thus, 0.05 or $0.1 \mu \mathrm{g} \cdot \mathrm{kg}^{-1} \cdot \mathrm{min}^{-1}$ remifentanil is safe and effective for sevoflurane maintenance of GA and is recommended in CD.

Some limitations to the present study should be noted. First, all patients underwent careful screening for an optional procedure and had not commenced delivery, so there was no opportunity to study changes in the demand for inhaled anesthetics after onset of labor. Additionally, all mothers had full-term pregnancies, and the impact on the Apgar score of premature infants cannot be taken into account. In addition, the algorithm for the Narcotrend index is a trade secret, and while the manufacturer believes that the D-E intervals represent a patient under anesthesia, more validation is needed to determine whether Narcotrend monitoring can completely avoid intraoperative awareness. Finally, the number of patient samples in this study is too small, and we will add a large sample study for verification in later studies.

In conclusion, our study showed that the EC50 and EC95 of sevoflurane were 0.798-0.819 MAC and 
Table 3 The effect of a graded dose of remifentanil combined with sevoflurane on the maternal and newborn status

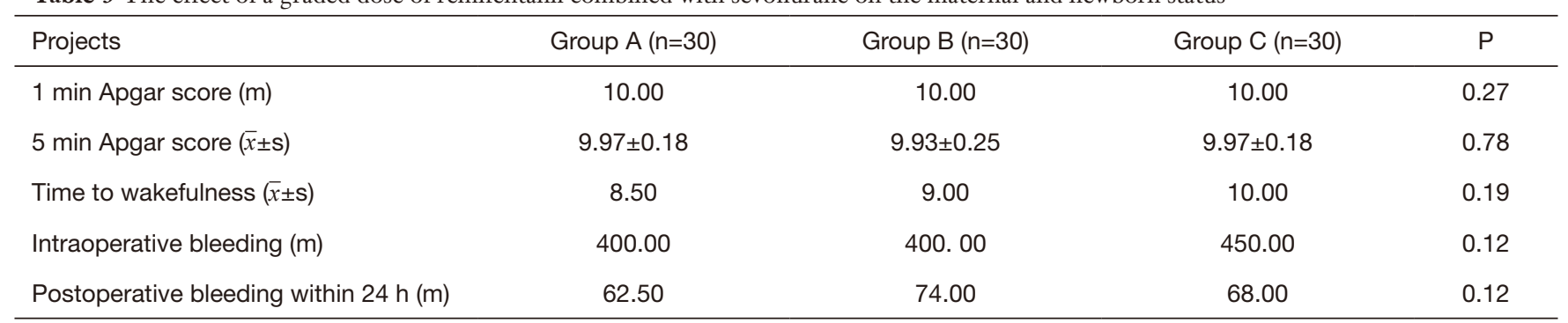

Data are mean \pm SD.

0.946-0.960 MAC, respectively, during CD under GA. Remifentanil $0.05-0.1 \mu \mathrm{g} \cdot \mathrm{kg}^{-1} \cdot \mathrm{min}^{-1}$ in coordination with sevoflurane did not reduce the EC50 of sevoflurane. Considering the dose-dependence of inhaled anesthetics on the inhibition of uterine contractions, we conclude that the concentration of inhaled anesthetics can be minimized with Narcotrend monitoring.

\section{Acknowledgments}

Funding: This study is supported by the Quanzhou Science and Technology Bureau Fund of China (2018Z157).

\section{Footnote}

Reporting Checklist: The authors have completed the CONSORT reporting checklist. Available at https://dx.doi. org/10.21037/apm-21-2664

Trial Protocol: Available at https://dx.doi.org/10.21037/apm21-2664

Data Sharing Statement: Available at https://dx.doi. org/10.21037/apm-21-2664

Conflicts of Interest: All authors have completed the ICMJE uniform disclosure form (available at https://dx.doi. org/10.21037/apm-21-2664). QSX reports that this study is supported by the Quanzhou Science and Technology Bureau Fund of China (2018Z157). The other authors have no conflicts of interest to declare.

Ethical Statement: The authors are accountable for all aspects of the work in ensuring that questions related to the accuracy or integrity of any part of the work are appropriately investigated and resolved. All procedures performed in this study involving human participants were in accordance with the Declaration of Helsinki (as revised in 2013). The study was approved by the Ethics Committee of Quanzhou Women's and Children's Hospital (No. 2020-1) and informed consent was taken from all the patients.

Open Access Statement: This is an Open Access article distributed in accordance with the Creative Commons Attribution-NonCommercial-NoDerivs 4.0 International License (CC BY-NC-ND 4.0), which permits the noncommercial replication and distribution of the article with the strict proviso that no changes or edits are made and the original work is properly cited (including links to both the formal publication through the relevant DOI and the license). See: https://creativecommons.org/licenses/by-nc-nd/4.0/.

\section{References}

1. Palanisamy A, Mitani AA, Tsen LC. General anesthesia for cesarean delivery at a tertiary care hospital from 2000 to 2005: a retrospective analysis and 10-year update. Int J Obstet Anesth 2011;20:10-6.

2. Guglielminotti J, Wong CA, Landau R, et al. Temporal Trends in Anesthesia-related Adverse Events in Cesarean Deliveries, New York State, 2003-2012. Anesthesiology 2015;123:1013-23.

3. Mhyre JM, Sultan P. General Anesthesia for Cesarean Delivery: Occasionally Essential but Best Avoided. Anesthesiology 2019;130:864-6.

4. Hamilton BE, Martin JA, Osterman MJ, et al. Births: Final Data for 2014. Natl Vital Stat Rep 2015;64:1-64.

5. Li HT, Luo S, Trasande L, et al. Geographic Variations and Temporal Trends in Cesarean Delivery Rates in China, 2008-2014. JAMA 2017;317:69-76.

6. World Health Organization. World health statistics 2015. Available online: http://www.who.int/gho/publications/ 
world_health_statistics/EN_WHS2015_Part2.pdf?ua=1. Accessed December 20, 2015.

7. Butwick AJ, Palanisamy A. Mode of anaesthesia for Caesarean delivery and maternal morbidity: can we overcome confounding by indication? Br J Anaesth 2018;120:621-3.

8. Guglielminotti J, Landau R, Li G. Adverse Events and Factors Associated with Potentially Avoidable Use of General Anesthesia in Cesarean Deliveries. Anesthesiology 2019;130:912-22.

9. Arslantas R, Umuroglu T. Comparing the effects of general and spinal anesthesia on the postoperative pain intensity in patients undergoing emergent elective cesarean section. Marm Med J 2019;32:62-7.

10. Ghaffari S, Dehghanpisheh L, Tavakkoli F, et al. The Effect of Spinal versus General Anesthesia on Quality of Life in Women Undergoing Cesarean Delivery on Maternal Request. Cureus 2018;10:e3715.

11. Juang J, Gabriel RA, Dutton RP, et al. Choice of Anesthesia for Cesarean Delivery: An Analysis of the National Anesthesia Clinical Outcomes Registry. Anesth Analg 2017;124:1914-7.

12. D'Angelo R, Smiley RM, Riley ET, et al. Serious complications related to obstetric anesthesia: the serious complication repository project of the Society for Obstetric Anesthesia and Perinatology. Anesthesiology 2014;120:1505-12.

13. Sumikura $H$, Niwa $H$, Sato $M$, et al. Rethinking general anesthesia for cesarean section. J Anesth 2016;30:268-73.

14. Mushambi MC, Kinsella SM. Obstetric Anaesthetists' Association/Difficult Airway Society difficult and failed tracheal intubation guidelines--the way forward for the obstetric airway. Br J Anaesth 2015;115:815-8.

15. Bercker S, Schmidbauer W, Volk T, et al. A comparison of seal in seven supraglottic airway devices using a cadaver model of elevated esophageal pressure. Anesth Analg 2008;106:445-8, table of contents.

16. Wong DT, Yang JJ, Jagannathan N. Brief review: The LMA Supreme ${ }^{\mathrm{TM}}$ supraglottic airway. Can J Anaesth 2012;59:483-93.

17. Li SY, Yao WY, Yuan YJ, et al. Supreme ${ }^{\mathrm{TM}}$ laryngeal mask airway use in general Anesthesia for category 2 and 3 Cesarean delivery: a prospective cohort study. BMC Anesthesiol 2017;17:169.

18. Yao WY, Li SY, Sng BL, et al. The LMA Supreme ${ }^{\mathrm{TM}}$ in 700 parturients undergoing Cesarean delivery: an observational study. Can J Anaesth 2012;59:648-54.

19. Han TH, Brimacombe J, Lee EJ, et al. The laryngeal mask airway is effective (and probably safe) in selected healthy parturients for elective Cesarean section: a prospective study of 1067 cases. Can J Anaesth 2001;48:1117-21.

20. Ngan Kee WD, Khaw KS, Ma KC, et al. Maternal and neonatal effects of remifentanil at induction of general anesthesia for cesarean delivery: a randomized, doubleblind, controlled trial. Anesthesiology 2006;104:14-20.

21. El-Tahan MR, El Kenany S, Abdelaty EM, et al. Comparison of the effects of low doses of dexmedetomidine and remifentanil on the maternal hemodynamic changes during caesarean delivery in patients with severe preeclampsia: a randomized trial. Minerva Anestesiol 2018;84:1343-51.

22. Kutlesic MS, Kutlesic RM, Mostic-Ilic T. Attenuation of cardiovascular stress response to endotracheal intubation by the use of remifentanil in patients undergoing Cesarean delivery. J Anesth 2016;30:274-83.

23. Yoon SW, Choi GJ, Seong HK, et al. Pharmacological strategies to prevent haemodynamic changes after intubation in parturient women with hypertensive disorders of pregnancy: A network meta-analysis. Int J Med Sci 2021;18:1039-50.

24. Van de Velde M. The use of remifentanil during general anesthesia for caesarean section. Curr Opin Anaesthesiol 2016;29:257-60.

25. Karaman S, Akercan F, Aldemir O, et al. The maternal and neonatal effects of the volatile anaesthetic agents desflurane and sevoflurane in caesarean section: a prospective, randomized clinical study. J Int Med Res 2006;34:183-92.

26. Pournajafian A, Rokhtabnak F, Kholdbarin A, et al. Comparison of remifentanil and fentanyl regarding hemodynamic changes due to endotracheal intubation in preeclamptic parturient candidate for cesarean delivery. Anesth Pain Med 2012;2:90-3.

27. Chin KJ, Yeo SW. A BIS-guided study of sevoflurane requirements for adequate depth of anaesthesia in Caesarean section. Anaesthesia 2004;59:1064-8.

28. Chin KJ, Yeo SW. Bispectral index values at sevoflurane concentrations of $1 \%$ and $1.5 \%$ in lower segment cesarean delivery. Anesth Analg 2004;98:1140-4.

29. Gencoglu NN, Kucukosman G, Aydin BG, et al. Effects of Preoperative Anxiety and General Anesthetic Administration on Intraoperative Awareness in Patients Undergoing Cesarean Section. Haseki Tip BulteniMedical Bulletin of Haseki 2019;57:114-21.

30. Yoo KY, Lee JC, Yoon MH, et al. The effects of volatile anesthetics on spontaneous contractility of isolated human 
pregnant uterine muscle: a comparison among sevoflurane, desflurane, isoflurane, and halothane. Anesth Analg 2006; 103:443-7, table of contents.

31. Turner RJ, Lambros M, Kenway L, et al. The in-vitro effects of sevoflurane and desflurane on the contractility of pregnant human uterine muscle. Int J Obstet Anesth 2002;11:246-51.

32. Savla JR, Ghai B, Bansal D, et al. Effect of intranasal dexmedetomidine or oral midazolam premedication on sevoflurane EC50 for successful laryngeal mask airway placement in children: a randomized, double-blind, placebo-controlled trial. Paediatr Anaesth 2014;24:433-9.

33. Wan L, Shao LJ, Liu Y, et al. Dexmedetomidine reduces sevoflurane EC50 for supraglottic airway device insertion in spontaneously breathing morbidly obese patients. Ther Clin Risk Manag 2019;15:627-35.

34. Ren LQ, Sun XX, Guan Y. Effects of sevoflurane or propofol combined with remifentanil anesthesia on clinical efficacy and stress response in pregnant women with pregnancy-induced hypertension. Eur Rev Med Pharmacol Sci 2018;22:1825-9.

35. Schmidt GN, Bischoff P, Standl T, et al. Narcotrend and Bispectral Index monitor are superior to classic electroencephalographic parameters for the assessment of anesthetic states during propofol-remifentanil anesthesia. Anesthesiology 2003;99:1072-7.

36. Fahy BG, Chau DF. The Technology of Processed

Cite this article as: Lian JF, Xu YB, Zheng BY, Shen LY, Liao DY, Zheng C, Lin CL, Huang CB, Luo QC, Guo GQ, Lin $\mathrm{XD}, \mathrm{Wu} \mathrm{JW}, \mathrm{Xiao} \mathrm{QS}$. Comparison of the median effective concentration (EC50) and effect of sevoflurane with or without remifentanil in cesarean section with supreme laryngeal mask under narcotrend monitoring: a randomized trial. Ann Palliat Med 2021;10(11):11578-11586. doi: 10.21037/apm-21-2664
Electroencephalogram Monitoring Devices for Assessment of Depth of Anesthesia. Anesth Analg 2018;126:111-7.

37. A. Pillai DB. Chestnut's Obstetric Anesthesia: Principles and Practice. Br J Anaesth 2015;5:861.

38. Erden V, Erkalp K, Yangin Z, et al. The effect of labor on sevoflurane requirements during cesarean delivery. Int J Obstet Anesth 2011;20:17-21.

39. Ueyama H, Hagihira S, Takashina M, et al. Pregnancy does not enhance volatile anesthetic sensitivity on the brain: an electroencephalographic analysis study. Anesthesiology 2010;113:577-84.

40. Brown EN, Lydic R, Schiff ND. General anesthesia, sleep, and coma. N Engl J Med 2010;363:2638-50.

41. Devroe S, Van de Velde M, Rex S. General anesthesia for caesarean section. Curr Opin Anaesthesiol 2015;28:240-6.

42. Orme RM, Grange CS, Ainsworth QP, et al. General anaesthesia using remifentanil for caesarean section in parturients with critical aortic stenosis: a series of four cases. Int J Obstet Anesth 2004;13:183-7.

43. McCarroll CP, Paxton LD, Elliott P, et al. Use of remifentanil in a patient with peripartum cardiomyopathy requiring Caesarean section. Br J Anaesth 2001;86:135-8.

44. Egan TD. Pharmacokinetics and pharmacodynamics of remifentanil: an update in the year 2000. Curr Opin Anaesthesiol 2000;13:449-55.

(English Language Editor: D. Fitzgerald) 